\title{
Morphologic and optical characterization of ZnO:Co thin films grown by PLD
}

\author{
M.V. Vuichyk ${ }^{1}$, Z.F. Tsybrii ${ }^{1}$, S.R. Lavoryk ${ }^{1,2}$, K.V. Svezhentsova ${ }^{1}$, I.S. Virt $^{3}$, A. Chizhov $^{4}$ \\ ${ }^{1} V$. Lashkaryov Institute of Semiconductor Physics, NAS of Ukraine, \\ 41, prospect Nauky,03028Kyiv, Ukraine,e-mail: tsybrii@isp.kiev.ua \\ ${ }^{2}$ LLC “NanoMed Tech” 68, Gor'kogo str., 03680 Kyiv, Ukraine \\ ${ }^{3}$ Ivan Franko Drohobych State Pedagogical University, \\ 24, I.Franko str., 82100 Drohobych, Ukraine \\ ${ }^{4}$ Lomonosov Moscow State University, Chemistry Department, \\ Leninskie Gory, 1/3, 119992, Moscow, Russian Federation
}

\begin{abstract}
The morphological properties of the surface and optical characteristics of nanocomposite $\mathrm{ZnO}$ :Co structures grown on substrates of monocrystalline silicon and sapphire by pulsed laser deposition (PLD) method have been studied. The influence of thermal annealing on formation of characteristically developed surface of films has been analyzed. The experimental transmission and reflectance spectra in the visible region have been measured. In the framework of the dielectric function, the optical constants $n$ and $k$ and dispersion parameters of oscillators that provide the best fit with experimental data have been obtained. From the infrared reflectance spectra of $\mathrm{ZnO}$ :Co structures, the frequency positions of $E_{1}(\mathrm{LO})$ and $E_{1}(\mathrm{TO})$ optical phonons have been determined. It gives a possibility to suppose that the obtained films possess the wurtzite structure.
\end{abstract}

Keywords: pulsed laser deposition, $\mathrm{ZnO}$ thin films, optical spectroscopy.

Manuscript received 21.11.13; revised version received 12.02.14; accepted for publication 20.03.14; published online 31.03.14.

\section{Introduction}

Recently, much attention is focused on scientific studies of thin films $\mathrm{ZnO}$, due to the prospects of its using as the basic elements for ultraviolet lasers, solar energy converters, gas sensitive sensors, transparent electrodes and others [1-3]. $\mathrm{ZnO}$ is a wide-band gap semiconductor that is non-absorbing over most of the solar spectrum. This material has the following attractive properties as a large band gap $(3.1-3.4 \mathrm{eV}$ in the bulk material), high electron mobility, strong luminescence, etc. With low cost, low temperature techniques, $\mathrm{ZnO}$ nanowires can be grown with a variety of morphologies. Theoretical studies suggest that layers with a suitable gradient-index of refraction can create both a broadband and directional anti-reflective coating [4].

Particular attention is focused on the study of thin film structures, doped by magnetic impurities, as these structures are promising to create devices for spintronics [5].

It is known that thermal annealing not only improves the crystalline properties of the films but leads to interaction between the film and impurities, especially at high temperatures $[6,7]$. Effect of annealing on the optical and electrical properties of the erbium doped $\mathrm{ZnO}$ thin films was studied in [6].

In this work, morphological and optical properties of $\mathrm{ZnO}$ thin films doped by cobalt were studied. The 
comparative analysis of the above-mentioned properties of annealed and unannealed $\mathrm{ZnO}$ :Co thin films has been carried out.

One of the non-destructive methods for investigations of semiconductor thin films and nanostructures, which allow checking its quality and structural perfection, is transmittance and reflectance spectroscopy. The aim of this work consists in the growth of structurally perfect thin films $\mathrm{ZnO}$ :Co by using different technological conditions and studying their morphological and optical properties.

\section{Experiments}

$\mathrm{ZnO}$ :Co thin films were grown using the pulsed laser deposition (PLD) method. Some practical criteria make deposition by PLD method promising for manufacturing these thin films. The major advantages of this method are as follows: low substrate temperature, good adhesion and high deposition rate, a comparatively wide range of energies of particles $(1 \ldots 1000 \mathrm{eV})$. Simplicity and benefits of PLD method has been successfully used for deposition of semiconductor compounds $\mathrm{A}_{2} \mathrm{~B}_{6}$.

The two types of $\mathrm{ZnO}: \mathrm{Co}$ films with a different thickness were obtained: on $\mathrm{Al}_{2} \mathrm{O}_{3}$ and $\mathrm{Si}$ substrates in vacuum close to $1 \cdot 10^{-5}$ Torr by using PLD. The samples were grown at the substrate temperature $300 \ldots 473 \mathrm{~K}$. The thickness of films was within the range 0.5 to $1 \mu \mathrm{m}$ depending on the number of laser pulses $[8,9]$.

After deposition of thin films, the samples were subjected to thermal annealing in air at $250{ }^{\circ} \mathrm{C}$ for optical activation of cobalt ions.

To study the morphology of the samples, the scanning probe microscope "FemtoScan" was used [10]. Measurements were carried out in the contact mode by using the silicon cantilevers. The nominal radius of curvature of the probe tip was $10 \mathrm{~nm}$.

Optical investigations (transmittance and reflectance) were performed within the range 200 to $2600 \mathrm{~nm}$ by using two-beam spectrophotometer Shimadzu UV-3600 and within the range 2 to $25 \mu \mathrm{m}$ by using the Fourier spectrometer "Perkin Elmer" Spectrum BXII. All the measurements were conducted at room temperature. Resolution of devices was better than $0.01 \mathrm{~nm}$. For comparison, the reflection and transmission spectra of substrates, on which the films were grown, were recorded.

\section{Results and discussion}

In Fig. 1, the three-dimensional AFM image of the surface morphology of $\mathrm{ZnO}$ :Co thin films grown on single crystal silicon substrates before (Fig. 1a) and after (Fig. 1b) thermal annealing are shown. Threedimensional AFM image of the surface morphology of $\mathrm{ZnO}$ :Co thin films grown on $\mathrm{Al}_{2} \mathrm{O}_{3}$ substrates before (Fig. 2a) and after (Fig. 2b) thermal annealing are shown in Fig. 2.
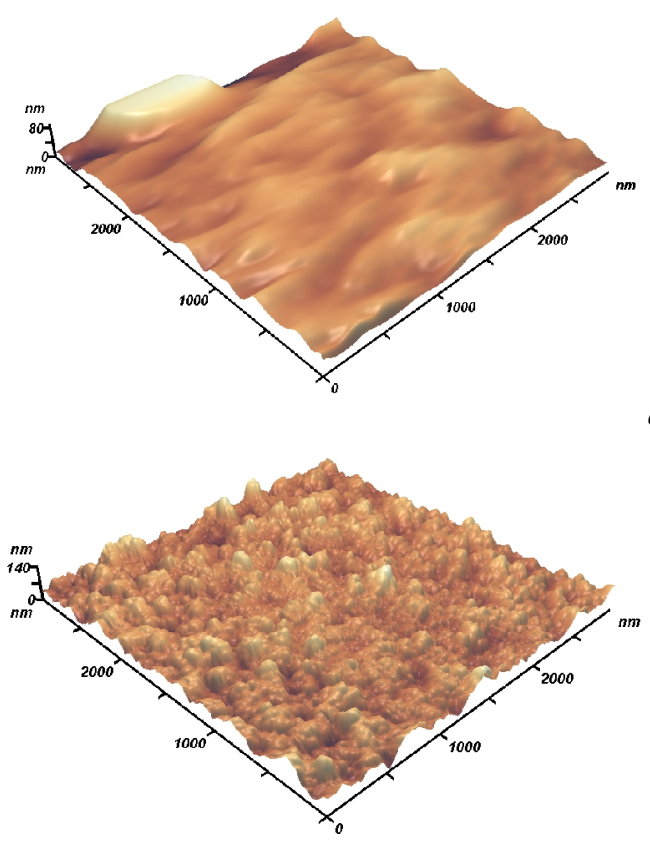

$b$

Fig. 1. Three-dimensional AFM image of surface morphology of $\mathrm{ZnO}: \mathrm{Co}$ thin films grown on monocrystalline silicon substrates, before (a) and after (b) thermal annealing.
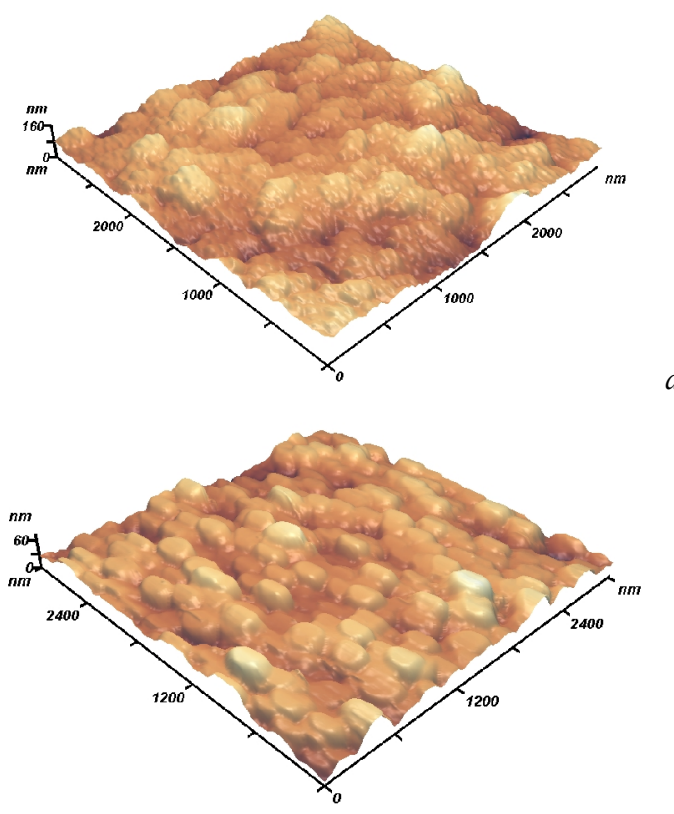

$b$

Fig. 2. Three-dimensional AFM image of surface morphology of $\mathrm{ZnO}$ :Co thin films grown on $\mathrm{Al}_{2} \mathrm{O}_{3}$ substrates, before (a) and after (b) thermal annealing.

As it can be seen from the images, the surface of unannealed $\mathrm{ZnO}$ :Co films on different substrates has no clearly pronounced structure, the roughness of surface is practically the same all-over the films. Annealing of the films at $250^{\circ} \mathrm{C}$ cardinally changes morphology of the surface (Figs $1 \mathrm{~b}$ and $2 \mathrm{~b}$ ), and in different ways on various substrates. So, $\mathrm{ZnO}$ :Co thin films grown on 
monocrystalline $\mathrm{Si}$ substrates after annealing are characterized by uniform nanostructure with the grain size 50 to $70 \mathrm{~nm}$, and their height is $10 \ldots 50 \mathrm{~nm}$. All grains have clearly pronounced tapered shape. In the case of $\mathrm{ZnO}$ :Co films grown on $\mathrm{Al}_{2} \mathrm{O}_{3}$ substrates, annealing leads to creation of homogeneous nanorelief with grains of a spherical shape. The lateral size of such grains varies from 250 to $300 \mathrm{~nm}$, and their height is $10 \ldots 20 \mathrm{~nm}$. In both cases, annealing increases the surface roughness.

In order to determine the optical parameters of $\mathrm{ZnO}$ :Co thin films, transmission and reflection spectra near the fundamental absorption edge were measured (Figs 3 and 4).

Comparing the transmission and reflection spectra of annealed samples and samples without annealing, one can see some differences in these spectra. These differences can be explained by that annealing leads to an improved crystalline structure of the films.

Thus, there is a shift of the fundamental absorption edge of the thin films. Both annealing and material of substrate effect on the magnitude of the shift. As it was mentioned above, annealing leads not only to improving of the crystalline structure of the films, but also strengthens the interaction between the film and impurities.

Band-gap can be estimated using the assumption of direct gap semiconductor transitions between the valence and conduction bands [11]. The dependence of the absorption coefficient $\alpha$ on the photon energy can be expressed as

$(\alpha h v)^{2}=A\left(h v-E_{g}\right)$,

where $A$ is some constant. The value of band-gap is obtained by extrapolation of the linear part of the curves as functions of photon energy of the incident radiation to the intersection with the energy axis (at $\alpha=0$ ).

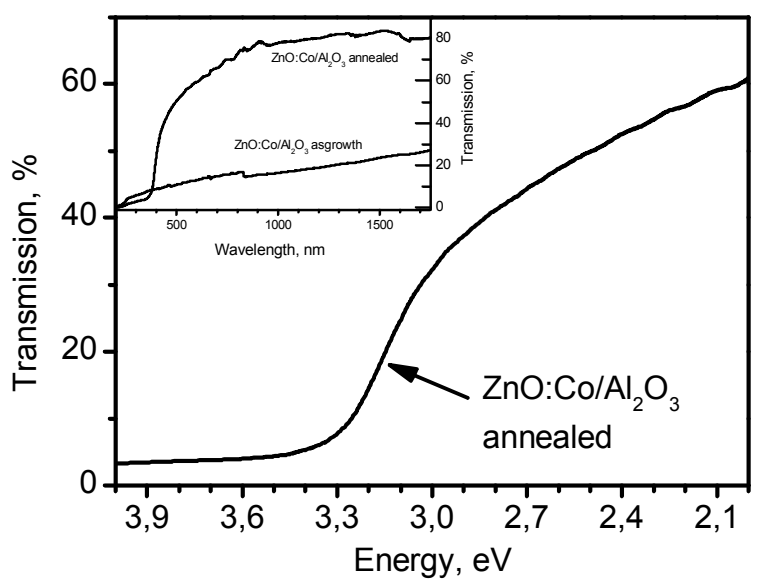

Fig. 3. Transmission spectrum of $\mathrm{ZnO}$ :Co thin film grown on $\mathrm{Al}_{2} \mathrm{O}_{3}$ substrate, after annealing. Transmission spectra of annealed and unannealed $\mathrm{ZnO}: \mathrm{Co} / \mathrm{Al}_{2} \mathrm{O}_{3}$ thin films in dependence on the wavelength are shown in the inset.

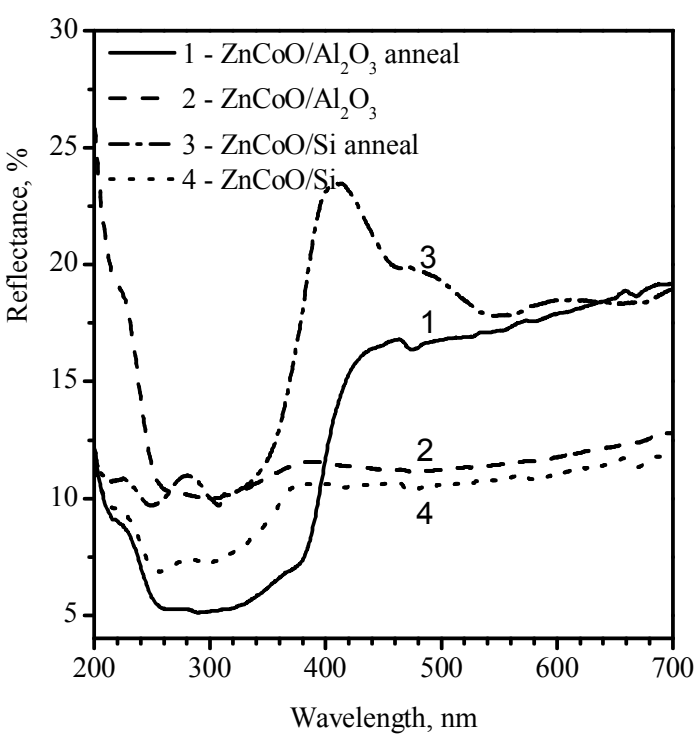

Fig. 4. Reflectance spectra of $\mathrm{ZnO}$ :Co thin films grown on different substrates, before and after annealing.

Calculation of the band-gap for the annealed sample grown on $\mathrm{Al}_{2} \mathrm{O}_{3}$ substrate gives the value $3.32 \mathrm{eV}$ that corresponds to the band-gap of bulk $\mathrm{ZnO}$. The calculated value of band-gap for annealed $\mathrm{ZnO}: \mathrm{Co}$ thin films grown on $\mathrm{Si}$ is $3.10 \mathrm{eV}$. This value differs a little from the value of bulk $\mathrm{ZnO}$. Calculation of the band-gap of samples without annealing by this method has some difficulties. In zinc oxide films, especially asgrown, there is zinc excess and annealing of the structure leads to the decrease in the concentration of intrinsic defects. In [8], it was explained by the resorption of fluctuation clusters of inhomogeneity.

The shift of the absorption edge towards the highenergy side (Burstein-Moss shift) with increasing the band-gap is associated with increasing the carrier concentration. That is, these results indicate that annealing of structures increases the concentration of electrons in the conduction band. On the other hand, the mechanical stresses, appearing because of the lattice mismatching parameters on the film-substrate interface, effect on the shift of the absorption edge. In these films, this effect occurs because of different values of the shift of the absorption edge for the films grown on $\mathrm{Al}_{2} \mathrm{O}_{3}$ and Si substrates.

Analysis of experimental results obtained from the reflection spectra was carried out in the framework of the dielectric function model [12]. The dielectric function $\varepsilon(\lambda)$ within application of the method of dispersive analysis of reflectance spectra of thin films in the region of interband transitions is described by a set of Lorentz oscillators:

$$
\begin{aligned}
& \varepsilon(v)=\varepsilon_{1}(\lambda)+i \varepsilon_{2}(\lambda)=n^{2}-k^{2}+2 i n k= \\
& =\varepsilon_{\infty}+\sum_{n=1}^{N} \frac{S_{j} \lambda^{2}}{\lambda^{2}-\lambda_{0, j}^{2}-i \gamma_{j} \lambda} .
\end{aligned}
$$


Here, $\varepsilon_{\infty}$ is the high-frequency dielectric constant of the material, $\lambda_{0, j}, S_{j}$ and $\gamma_{j}$ are the resonance wavelength, oscillator strength and width of the $j$-bands, respectively, all of which are treated as an adjustable parameters. Then, using the found parameters, the reflection spectrum of a thin film is reconstructed and compared to the experimental data with following optimization of the dispersion parameters.

Thus, after processing the spectra we have optical constants $n$ and $k$, the experimental and model spectra and dispersion parameters of oscillators that provide the best fit. Table shows the optical constants of $\mathrm{ZnO}: \mathrm{Co}$ films grown on different substrates before and after annealing.

Fig. 5 shows the reflection spectra in the farinfrared region of $\mathrm{ZnO}$ : $\mathrm{Co}$ thin films grown on $\mathrm{Al}_{2} \mathrm{O}_{3}$ substrates. The spectra were recorded at room temperature with the resolution $2 \mathrm{~cm}^{-1}$. Reflection spectra of the film before annealing (curve 2) are similar to the reflection spectrum of the substrate.

Analyzing the reflection spectra of $\mathrm{ZnO}$ :Co films, it is necessary to keep in mind that the structure of wurtzite belongs to space group $P 6_{3} m c$. The groups theory implies the existence of the nine branches of optical phonons $A_{1}+2 B_{1}+E_{1}+2 E_{2}$, some of which are doubly degenerated branch $E_{1}$ and totally symmetrical branch $A_{1}$ that are active in both Raman and infrared spectra. The optical modes $E_{2}$ are active only in Raman scattering, modes $B_{1}$ are not registered. Therefore, the following optical modes can be registered in the infrared spectra: $A_{1}(\mathrm{LO})=579 \mathrm{~cm}^{-1}, \quad A_{1}(\mathrm{TO})=380 \mathrm{~cm}^{-1}, \quad E_{1}(\mathrm{LO})=$ $591 \mathrm{~cm}^{-1}, \quad E_{1}(\mathrm{TO})=413 \mathrm{~cm}^{-1}$. Sphalerite structure contains one formular unit and at the point $\Gamma$ of Brillouin zone of sphalerite the optical branch is triply degenerated with frequencies: $\mathrm{TO}=403 \mathrm{~cm}^{-1}$ and $\mathrm{LO}=$ $558 \mathrm{~cm}^{-1}[9,13]$.

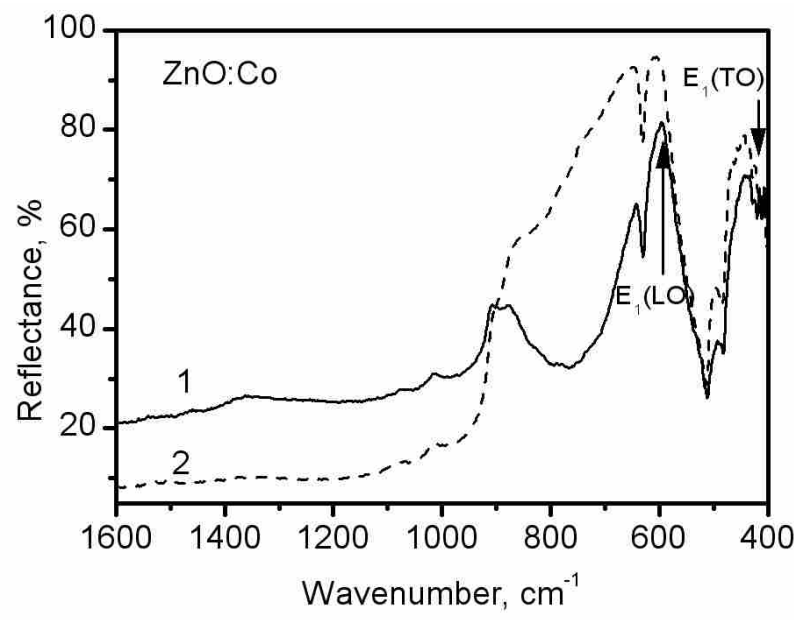

Fig. 5. Reflectance spectra of $\mathrm{ZnO}$ :Co thin films grown on $\mathrm{Al}_{2} \mathrm{O}_{3}$ substrates, before (2) and after (1) annealing.
Table. Optical parameters of $\mathrm{ZnO}$ :Co thin films grown on different substrates, before and after annealing.

\begin{tabular}{|c|c|c|c|}
\hline Sample & Annealing & $n$ & $k$ \\
\hline $\mathrm{ZnO}: \mathrm{Co} / \mathrm{Al}_{2} \mathrm{O}_{3}$ & - & 2.45 & 0.88 \\
\hline $\mathrm{ZnO}: \mathrm{Co} / \mathrm{Al}_{2} \mathrm{O}_{3}$ & + & 2.29 & 0.23 \\
\hline $\mathrm{ZnO}: \mathrm{Co} / \mathrm{Si}$ & - & 3.11 & 0.62 \\
\hline $\mathrm{ZnO}: \mathrm{Co} / \mathrm{Si}$ & + & 2.97 & 0.95 \\
\hline
\end{tabular}

Fig. 5 shows the spectral diapason that contains almost all the active optical phonons, which gives information about the degree of perfection inherent to the crystal structure in the investigated films. Dominating in this range oscillatory modes of substrate prevent the analysis of optical phonons. In order to avoid the influence of the substrate, the reflectance spectrum of substrate was recorded in the same range. Subtraction of reflection spectrum of the substrate from reflectance spectra of the film-substrate system allows an assumption that thin films have the wurtzite type crystal structure. However, it should be noted that the frequency position of the optical phonons $E_{1}(\mathrm{LO})=588 \mathrm{~cm}^{-1}$ and $E_{1}(\mathrm{TO})=411 \mathrm{~cm}^{-1}$ are slightly shifted relative to the theoretical values. The reasons for this could be either the presence of mechanical stress in the films, which are determined by the lattice parameter mismatching of the film and substrate, or the effect of cobalt (formation of solid solution $\mathrm{Zn}_{1-\mathrm{x}} \mathrm{Co}_{\mathrm{x}} \mathrm{O}$ ). To accurately answer these questions, it is necessary to perform additional structural studies of these thin films.

\section{Conclusions}

The morphological surface properties and optical characteristics of nanocomposite structures $\mathrm{ZnO}: \mathrm{Co}$ grown on different substrates have been studied. The value of the band-gap for these structures has been calculated. It has been shown that thermal annealing leads to a decrease in the concentration of intrinsic defects, and the band-gap value is close to the value of bulk crystals. Through the comparative analysis of experimental and model data within the model of dielectric function, optical constants $n$ and $k$, the experimental and model spectra in the visible region of the spectrum and dispersion parameters of oscillators that provide the best fit have been obtained. From the reflectance spectra in the infrared region, the frequency positions of optical phonons $E_{1}(\mathrm{LO})$ and $E_{1}(\mathrm{TO})$ have been defined, which allows to assume the wurtzite structure of the obtained films.

\section{Acknowledgement}

This work was partially sponsored by Ukrainian-Russian Research Project "Developing of photo- and gas sensitive nanocomposites on the base of semiconductor oxides that are sensibilized by II-VI quantum dots". 


\section{References}

1. M. Zamfirescu, A. Kavokin, B. Gill, G. Malpuech, M. Kaliteevski, $\mathrm{ZnO}$ as a material mostly adapted for the realization of room-temperature polariton lasers // Phys. Rev. B, 65, p. 161205(R) (2002).

2. V.A. Krivchenko, D.V. Lopaev, P.N. Paschenko, V.G. Pirogov, A.T. Rakhimov, N.V. Suetin, A.S. Trifonov, UV-radiation detectors based on $\mathrm{ZnO}$ nanocrystalline films // Technical Physics, 78(8), p. 107-111 (2008).

3. A.F. Belyanin, V.A. Krivchenko, D.V. Lopaev, L.V. Pavlushkin, P.N. Paschenko, V.G. Pirogov, S.N. Polyakov, N.V. Suetin, N.I. Sushentsov, Nanostructuring of $\mathrm{ZnO}$ films for microelectronics and optical devices // Tekhnologiya i konstruirov. $v$ elektron. apparature, 6, p. 48-55 (2006), in Russian.

4. Martha Coakley, Growth and Optical Characterization of Zinc Oxide Nanowires for AntiReflection Coatings for Solar Cells. Dissertation and Theses. Paper 290, 2011, http://pdxscholar.library.pdx.edu/open_access_etds

5. F. Pan, C. Song, X.J. Liu, Y.C. Yang, F. Zeng, Ferromagnetism and possible application in spintronics of transition-metal-doped $\mathrm{ZnO}$ films // Mater. Sci. and Eng. R, 62, p. 1-35 (2008).

6. J. Hays, A. Thurber, K.M. Reddy, A. Punnoose, M.H. Engelhard, Development and processing temperature dependence of ferromagnetism in $\mathrm{Zn}_{0.98} \mathrm{Co}_{0.020} / /$ J. Appl. Phys., 99(8), p. 08M12308M123-3 (2006).

7. N.R. Aghamalyan, R.K. Ovsepian, E.A. Kafadaryan, R.B. Kostanyan, S.I. Petrosyan, G.O. Shirinyan,
M.N. Nersinyan, A.H. Abduyev, A.S. Asvarov, Effect of annealing on the optical and electrical properties of $\mathrm{ZnO}$ : Er films // Izvestiya Armian. Natsional. Akademii Nauk, Fizika, 43(3), p. 224-232 (2008), in Russian.

8. I.V. Kurylo, I.O. Rudy, I.Ye. Lopatynski, M.S Frunzhinsky, I.S. Virt, P. Potera, G. Luka, Structural and optical properties $\mathrm{ZnO}$ and $\mathrm{ZnMnO}$ thin films // Visnyk Natsional. Universitety “Lvivska politekhnika”, Elektronika, 708, p. 24-30 (2011), in Ukrainian.

9. A.V. Bazhenov, T.N. Fursova, M.Y. Maksymchuk, E.M. Kaidashev, V.E. Kaidashev, O.V. Misochko, Growth of $\mathrm{ZnO}$ nanocrystals by pulsed laser deposition on sapphire and silicon and the infrared spectra of the nanocrystals // Semiconductors, 43(11), p. 1532-1538 (2009).

10. A.S. Rykov, Scanning Probe Microscopy of Semiconductor Materials and Nanostructures. Nauka, St. Petersburg, 2001.

11. R.E. Marotti, D.N. Guerra, C. Bello, G. Machado, E.A. Dalchiele, Bandgap energy tuning of electrochemically grown $\mathrm{ZnO}$ thin films by thickness and electrodeposition potential // Solar Energy Materials \& Solar Cells, 82, p. 85-103 (2004).

12. John T. Foley, Uzi Landman, Model dielectric function for semiconductors: Si // Phys. Rev. B, 14(4), p. 1597-1604 (1976).

13. K.A. Alim, V.A. Fonoberov, M. Shamsa, A.A. Balandin, Micro-Raman investigation of optical phonons in $\mathrm{ZnO}$ nanocrystals // J. Appl. Phys. 97, 124313-1-124313-5 (2005). 